\title{
Aortic stenosis, sudden death, and the left ventricular baroceptors
}

\author{
A. M. Johnson ${ }^{1}$
}

Sudden death in patients with aortic stenosis has not yet received adequate explanation and the importance of left ventricular baroceptors in this has not, to the writer's knowledge, been suggested. Nor, indeed, does the existence of left ventricular baroceptors appear to have been acknowledged in cardiology.

The purpose of this editorial is to consider the magnitude and significance of the problem of sudden death in the presence of aortic valve stenosis and to suggest, from evidence already existing in the cardiological, physiological, and pharmacological literature, a new hypothesis for the mechanism of syncope and sudden death in this disease.

The disordered physiology present with aortic stenosis is unique to this condition. The systolic pressures within the left ventricle and within the aorta, normally identical

$\checkmark$ and controlled together by the cardiovascular reflexes, are in this disease divorced from one another haemodynamically; but the systolic

$r$ pressure in the left ventricle continues to influence the state of the peripheral vascular

- bed by reflex pathways. Thus, the writer wishes to suggest that in this unique state of

- affairs the peripheral systemic vasculature is inappropriately affected by reflex activity arising from baroceptors situated within the 3. left ventricular myocardium. Normally, left ventricular and aortic systolic pressures rise - and fall together and the importance of the carotid and aortic baroceptors in the regula- tion of blood pressure is well recognized. In the presence of aortic stenosis, however, a

- rise of left ventricular pressure is not accompanied by a corresponding rise of aortic pressure. Impulses arising from left ventricular - baroceptors may have the same effect as those arising from the carotid and aortic baroceptors - and result in bradycardia, a common and

\footnotetext{
4ardiac and Thoracic Unit, Southampton Chest Hospital, Millbrook, Southampton.
}

hitherto unexplained feature of severe aortic stenosis, and a fall in peripheral systemic vascular resistance. A powerfully initiated reflex resulting from a very severe rise in left ventricular systolic pressure would thus produce hypotensive syncope, coronary blood flow would be reduced at a time of maximal left ventricular work, and death would occur from ventricular fibrillation. The irreversibility of ventricular fibrillation in the presence of unrelieved severe aortic stenosis was well recognized by surgeons at the operating table in the days of closed aortic valvotomy.

\section{Incidence and predictability}

From a review of the published papers over the previous century, Marvin and Sullivan (1935) found that the association between aortic stenosis and sudden death was not much commented upon until Cabot (I926), from a study of postmortem records, drew attention to the fact that in 6 of 28 cases of aortic stenosis 'death was notably sudden and unexpected'. Reynolds et al. (1960), in a paper reporting sudden death in a child with aortic stenosis and minimal electrocardiographic changes and operation in a sib with the same, quoted from published work an incidence of between 4 and 18 per cent with an average of 7.5 per cent. The special reason for their paper was that they had earlier reported severe electrocardiographic abnormalities in all children dying suddenly with aortic stenosis and were anxious to correct the impression that minimal cardiographic abnormalities could be taken as a guarantee against sudden death.

Glew et al. (1969) found from published material an incidence between 6 and 19 per cent of sudden death in children with aortic stenosis, but in their own paediatric experience an incidence of only I per cent. They stressed that in all the published series they had studied and in their own patients there had always been evidence of severe cardiac disease in one or 
more ways, namely in the symptoms, in the clinical signs, or in the electrocardiogram. 'Therefore, death in congenital aortic stenosis may be sudden, but it should not be unexpected.' These authors emphasized also the importance of haemodynamic assessment by cardiac catheterization if any doubt exists regarding the severity of aortic stenosis; and that even mild cases of congenital aortic stenosis may progress in severity; so that every such patient requires 'careful and extended follow up with sequential physical examinations and electrocardiograms', and cardiac catheterization or a repeat thereof should be carried out in the event of deterioration in any single criterion. It is vitally important to recognize that all the criteria of severity of aortic stenosis in any given individual, and especially in children, may not exist in the same degree or progress at the same tempo. Thus, physical signs may indicate severe aortic stenosis in a symptomless child with minimal electrocardiographic abnormalities. Detailed assessment by cardiac catheterization would be indicated in such a patient.

In the writer's own series of 204 cases of aortic valve stenosis seen in adults over the past 8 years, 130 were severe and of these 27 died suddenly, an incidence of 21 per cent. No single criterion or group of criteria was found by which sudden death could have been predicted, but all who died in this way had severe aortic stenosis and no case of sudden death has occurred in an adult with mild or moderate stenosis. In the same period, II adults have died from heart failure without surgery and 72 adults have undergone aortic valve surgery. Also within the same period of time 65 children with aortic valve stenosis have been seen, of whom I aged II years with severe stenosis, whose parents refused to allow cardiac investigation, died suddenly 3 months later. Three have undergone aortic valve surgery and the remaining $6 \mathrm{I}$, with mild or moderate stenosis, have continued under observation.

\section{Significance}

It is 13 years since Brock (1957) aroused physicians to awareness of an opportunity, which then existed for the first time, to bring surgical relief to patients with severe aortic valve stenosis; and exhorted them not to delay too long before seeking the surgeon's help. Left ventricular failure may now be regarded as an accidental occurrence during surveillance of a patient rather than as the event awaited before operation is considered advisable. Operative mortality is now sufficiently small and the outlook after operation so much better than the natural history of severe aortic valve stenosis that the incidence of sudden death has assumed real importance. The writer cannot escape the conclusion from the high risk of sudden death in patients awaiting cardiac investigation or aortic valve operation, that these patients should be considered in a category of urgency special to this condition. Since sudden death may occur even when the patient is quiet (though it is more common during exertion), leading a quiet life at home does not remove the risk of sudden death and the lost opportunity.

\section{Mechanism: present theories}

Flamm et al. (1967), in reporting careful and important haemodynamic studies during effort which induced near syncope in patients with aortic stenosis, noted that one or other of two mechanisms was usually postulated to account for this syncope; either sudden arrhythmia or insufficient rise in cardiac output. These workers subjected 26 patients with aortic stenosis to erect exercise by treadmill walking. Two patients experienced near syncope and in one of them serial haemodynamic measurements were made. Initially, there was a rise in cardiac output $(4.6$ to $14.51 . / \mathrm{min}$.) and arterial pressure (139/84 to $165 / 8 \mathrm{Imm}$. $\mathrm{Hg}$ ), but with the onset of near syncope there was a fall in cardiac output $(4.4 \mathrm{l} . / \mathrm{min}$.) and arterial pressure $(44 / 32 \mathrm{~mm}$. $\mathrm{Hg})$. Systemic vascular resistance, which had been $21 \mathrm{~mm}$. $\mathrm{Hg} / \mathrm{l}$./min. at rest, fell to 8 to $9 \mathrm{~mm}$. $\mathrm{Hg} / \mathrm{l}$./ $\mathrm{min}$. throughout exercise and the brief hypotensive period. In 29 patients exercised in the supine position syncope or hypotension never developed, and ro of these patients showed normal increase in cardiac output, as had been the case in the erect patients until the point of syncope was reached. 'Significant arrhythmias' did not occur in any of these studies. Flamm et al. concluded that 'effort syncope occurs in patients with aortic stenosis who are able to increase their cardiac output substantially but who develop left ventricular failure at critical levels of exercise, with an abrupt fall in cardiac output, without an appropriate increase in systemic vascular resistance (my italics) resulting in a marked fall in arterial pressure'.

Thus, they supported the theory of failure of further rise in cardiac output at a critical work level, due to acute left ventricular failure. Their evidence for the latter was a rise of left ventricular end-diastolic pressure during the exercise. They did not comment further upon their failure to produce syncope or hypoten- 
sion in the supine patients in whom all other findings were exactly similar to those in the erect patients.

Schwartz et al. (1969) observed the clinical manifestations and continuously recorded the electrocardiogram in 9 adult patients with aortic stenosis before, during, and after syncopal seizures; and the mode of sudden death was registered by the 'cardiac arrest' team of the hospital in 12 other patients with aortic stenosis. A sudden drop in blood pressure, pallor, absent pulses and heart sounds, and the disappearance of the aortic murmurs accompanied loss of consciousness. Up to 40 seconds of regular sinus rhythm usually persisted, but there were QRS and ST segment changes. After 40 seconds total cardiac standstill, ventricular standstill, ventricular flutter, or ventricular fibrillation occurred and death resulted. The authors remarked that the electrocardiographic abnormalities were similar to those obtained during experimental and clinical coronary artery obstruction and diminished coronary arterial blood flow; and they noted that syncope in aortic stenosis may be preceded or followed by angina pectoris. They concluded that 'syncope and sudden death in patients with aortic stenosis is an expression of diminished coronary arterial blood flow as a result of acute ventricular failure and diminished cardiac output in a diseased heart' (my italics).

The suggestion of Marvin and Sullivan (1935) that hyperactivity of the carotid sinus reflex, combined with aortic stenosis, might be the cause of syncope and sudden death in these patients has not received much further consideration since it was made. They themselves saw a major difficulty in accepting this theory, notably that sudden death had not been reported in patients known to have hyperactivity of this reflex. Even so, they concluded: 'It is our belief that the cause is probably either (a) the combination of aortic stenosis and hyperactive carotid sinus reflex, or (b) the same mechanism that terminates life in many patients who have anginal heart failure or who have sustained recent thrombosis of a coronary artery. It seems to be the prevailing opinion that this mechanism is dependent upon the onset of ventricular fibrillation or upon a depressor reflex other than that involving the carotid sinus, but conclusive evidence of its precise nature is yet to be obtained' (my italics).

\section{Mechanism: new hypothesis}

I It is suggested that all the observations marshalled in these three papers may be accounted for by the presence of baroceptors in the left ventricular wall, responsive to a severe rise of left ventricular systolic pressure and initiating a depressor reflex to produce bradycardia, peripheral systemic vasodilatation, and dilatation of the splanchnic bed. Diminished venous return with diminished cardiac output, together with lowered systemic vascular resistance, results in severe hypotension and syncope; coronary arterial blood flow falls abruptly in the face of heavy left ventricular work, and myocardial ischaemia causes angina if there is recovery from syncope, or arrhythmias cause final arrest of the circulation and death ensues.

\section{Left ventricular baroceptors and depres- sor reflex}

It remains, therefore, to present the evidence for the existence of left ventricular baroceptors and the depressor reflex initiated by them, which, the writer suggests, is the cause of syncope and sudden death in patients with aortic stenosis.

Observations reported without interpretation (Johnson and Logan, 1958) first led the writer to suspect the presence of baroceptors in the left ventricular myocardium. The effects of thrice repeated introduction and withdrawal of a cardiac catheter into and from the right coronary artery of a ro-year-old girl were described. At each insertion, ST segment depression in lead I (the only monitored lead) and a rise of aortic pressure were seen; and the pressure returned to the initial normal level when the catheter, after the third withdrawal, was left free in the aortic root for some minutes. It rose again when the catheter was finally reinserted and ro $\mathrm{ml}$. sodium atrizoate were injected. There was a further rise after a second injection, this time into the aortic root, which filled the right coronary artery from the aorta. The aortic pressure was initially $135 / 71 \mathrm{~mm}$. $\mathrm{Hg}$ and finally $159 / 107$ $\mathrm{mm}$. Hg. The electrocardiogram showed sinus tachycardia of $144 / \mathrm{min}$. and the appearances of acute posterior myocardial infarction. At no time during these observations was there either hypotension or general hypoxia. It seemed possible that left ventricular myocardial baroceptors might have been put out of action by myocardial anoxia, so diminishing the afferent impulse from the left ventricle and mimicking the presence of hypotension; and that tachycardia and peripheral systemic vasoconstriction with consequent hypertension were the result of this 'misinterpretation' of a reduced total afferent impulse from left ventricular baroceptors.

It recently occurred to the writer that the 
syncope of aortic stenosis might be the reciprocal of these observed effects. An abrupt rise of left ventricular systolic pressure, without a corresponding rise of aortic pressure, might so stimulate left ventricular baroceptors as to produce violent depressor reflex effects. Bradycardia, peripheral vasodilatation, and perhaps splanchnic bed dilatation would result in diminished cardiac output with hypotensive syncope, impaired coronary arterial flow, and a terminal arrhythmia causing sudden death.

What, then, is the evidence for the existence of left ventricular baroceptors and their vasomotor inhibitory function? The writer has used the monograph of Heymans and Neil (1958) as the starting point of his researches into the physiological literature, and gratefully acknowledges the revelations which their work has provided.

Cyon and Ludwig (1866) discovered the depressor (aortic) nerve and believed that it arose from endings in the heart itself and that its sensory endings were responsive to changes of intracardiac pressure. Too strong a heart beat would produce reflex bradycardia and hypotension. In 1867, Bezold and Hirt described reflex bradycardia and hypotension produced by the injection of veratrine; and it was shown many years later (Paintal, 1955) that veratrine excited cardiac receptors which appeared to serve a function such as Cyon and Ludwig (I866) described. Cramer (I915) was the first to realize that systemic hypotension produced by veratrine was independent of bradycardia and was due to reflex peripheral vasodilatation. Daly and Verney (1926) produced the first direct evidence that pressoreceptors exist in the left heart. By raising the pressure in both the coronary arteries and the left ventricle in the innervated heart, while keeping the aortic pressure constant, they produced slowing of the heart. King (1939), by in vivo injections of methylene blue in the rat, showed a variety of forms of cardiac nerve endings, one of which was commonly found in the ventricles and not in the aorta. He considered these to be stretch receptors. Amann and Schaefer (1943) described the impulses which may be recorded from the cut central end of the right cardiac vagal branches. Bursts of impulses occurred synchronously with atrial and ventricular contractions and these authors concluded that the large spike potentials which they recorded arose from nerve endings in the atria and ventricles. Jarisch and Zotterman (1948) were able to distinguish differences between impulses arising from the atria and those from the ventricles. Large spiked potentials resulted from atrial stimulation, while ventricular stimulation produced small, slowly conducted spikes which these workers considered were conducted by thin afferent fibres of the cardiac vagal branches. They pointed out the preponderance of thin fibres in these nerves and showed that electrical stimulation of the central ends of these branches, if effective at all, caused reflex bradycardia and hypotension. Neil and Zotterman (1950), by showing that bradycardia and hypotension resulted only when electrical stimulation was powerful enough to excite the thin fibres of the cardiac vagal branches, indicated that these reflex effects were mediated through the thin fibres; and from this it seems that the ventricle is the main or only cardiac source of impulses initiating this reflex. Whitteridge (1948) recorded impulse activity in few-fibre preparations of cardiac vagal afferents made by dissecting the cervical vagus. In addition to identifying fibres from the atria, he isolated fibres which showed a volley of impulses occurring at the very beginning of ventricular systole, and suggested that these fibres arose from ventricular nerve endings stimulated by the rise of tension in the ventricular wall during isometric contraction. Aviado et al. (1951a, b) showed that a rise in pressure in the vascularly isolated left heart caused reflex bradycardia and dilatation of the leg vessels. A rise of pressure in the left atrium alone produced no such effect and it was concluded that the receptors responsible were situated in the left ventricle. Vagotomy abolished the reflex.

\section{Conclusions}

Heymans and Neil (1958) point out that many questions remain regarding this mechanism, and one of these is whether the left ventricular receptors exert a tonic influence upon the medullary (parasympathetic) centres. They consider it likely that a proportion of reflex vagal tone is due to these receptors as well as to those in the sino-aortic areas; and if this is the case it seems extremely likely that syncope in aortic stenosis results from a large increase of the left ventricular contribution to vagal tone which results in reflex bradycardia and hypotension, and that sudden death is the result of diminished coronary flow secondary to these reflex changes.

There arise out of this hypothesis several questions regarding the management of patients with severe aortic stenosis who are awaiting aortic valve operation and who are at risk from sudden death. Can vagolytic drugs diminish the risk? May the vagolytic tranquillizers have a useful place in this connexion? Does digitalis, by stimulation of the 
vagus centre, increase the chance of sudden death? In a patient who is for some reason considered unsuitable for aortic valve operation, should cervical vagotomy be considered ?

Certainly the risk of sudden death in adults with severe aortic valve stenosis is sufficient to justify placing them in the urgent category on the surgeon's waiting list; and no doubt the same applies to children with severe stenosis.

My thanks are due to K. A. Munday, Professor of Physiology and Biochemistry in the University of Southampton, and his staff, for help in searching published material for evidence of the existence of left ventricular baroceptors; and to my own staff for help with translation from the German.

\section{References}

Amann, A., and Schaefer, H. (1943). Über sensible Impulse im Herznerven. Pflügers Archiv für die gesamte Physiologie des Menschen und der Tiere, 246, 757.

Aviado, D. M., Li, T. H., Calesnick, B., and Bell, R. (19512). Cardio-vascular adjustments to pressure changes in left ventricle and peripheral arteries. Federation Proceedings, 10, 7.

, - Kalow, W., Schmidt, C. F., Turnbull, G. L., Peskin, G. W., Hess, M. E., and Weiss, A. J. (195Ib). Respiratory and circulatory reflexes from the perfused heart and pulmonary circulation of the dog. American fournal of Physiology, 165, $26 r$.

Bezold, A. von, and Hirt, L. (1867). Ueber die physiologischen Wirkungen des essigsauren Veratrin's. In Untersuchungen aus der physiologischen Laboratorium in Würzburg, part $\mathrm{I}, \mathrm{p} .73$. Ed. by $\mathrm{A}$. von Bezold. Engelmann, Leipzig.

Brock, R. C. (1957). Surgical treatment of aortic stenosis. British Medical fournal, 1, rorg.

Cabot, R. C. (1926). Facts on the Heart. Saunders, Philadelphia.

Cramer, W. (1915). On the action of veratrum viride. Fournal of Pharmacology and Experimental Therapeutics, 7, 63 .

Cyon, E., and Ludwig, C. (1866). Die Reflexe eines der sensiblen Nerven des Herzens auf die motorischen der Blutgefässe. Berichte über die Verhandlungen der Königlich sächsischen Gesellschaft der Wissenschaften zu Leipzig. Mathematisch-physische Classe, 18, 307.

Daly, I. de B., and Verney, E. B. (1926). Cardiovascular reflexes. Fournal of Physiology, 61, 268.

Flamm, M. D., Braniff, B. A., Kimball, R., and Hancock, E. W. (1967). Mechanism of effort syncope in aortic stenosis. Circulation, 36, Suppl. II, I09.

Glew, R. H., Varghese, P. J., Krovetz, L. J., Dorst, J. P., and Rowe, R. D. (1969). Sudden death in congenital aortic stenosis. A review of 8 cases with an evaluation of premonitory clinical features. American Heart fournal, 78, 615 .

Heymans, C., and Neil, E. (1958). Reflexogenic Areas of the Cardiovascular System. Churchill, London.

Jarisch, A., and Zotterman, Y. (1948). Depressor reflexes from the heart. Acta Physiologica Scandinavica, 16, 31.

Johnson, A. M., and Logan, W. D. (1958). Coronary artery catheterization during thoracic aortography. British Heart fournal, 20, $4 \mathrm{I}$ I.

King, A. B. (1939). Nerve endings in the cardiac muscle of the rat. Bulletin of the fohns Hopkins Hospital, 65, 489.

Marvin, H. M., and Sullivan, A. G. (1935). Clinical observations upon syncope and sudden death in relation to aortic stenosis. American Heart fournal, ro, 705.

Neil, E., and Zotterman, Y. (1950). Cardiac vagal afferent fibres in the cat and the frog. Acta Physiologica Scandinavica, 20, 160.

Paintal, A. S. (1955). Impulses in vagal afferent fibres from specific pulmonary deflation receptors. The response of these receptors to phenyl diguanide, potato starch, 5-hydroxytryptamine and nicotine, and their rôle in respiratory and cardiovascular reflexes. Quarterly fournal of Experimental Physiology, 40, 89.

Reynolds, J. L., Nadas, A. S., Rudolph, A. M., and Gross, R. E. (I960). Critical congenital aortic stenosis with minimal electrocardiographic changes. A report on two siblings. New England fournal of Medicine, 262, 276.

Schwartz, L. S., Goldfischer, J., Sprague, G. J., and Schwartz, S. P. (1969). Syncope and sudden death in aortic stenosis. American fournal of Cardiology, 23, 647 .

Whitteridge, D. (1948). Afferent nerve fibres from the heart and lungs in the cervical vagus. Fournal of Physiology, 107, 496. 